\title{
Peertechz
}

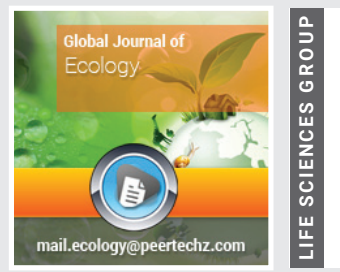

\section{The relative importance of multiple invasion mechanisms}

\author{
Yu-Fei Zhao', Shu-Qi Zhou', Zuo-Fu Wei ${ }^{2}$, Bao-Shan Zhao ${ }^{1}$ \\ and Li-Jia Dong ${ }^{1 *}$
}

${ }^{1}$ School of Life Science, Shaoxing University, Shaoxing 312000, China

${ }^{2}$ School of Life Science, Shanxi Normal University, Linfen, Shanxi 041004, China

Received: 24 July, 2019

Accepted: 01 December, 2020

Published: 02 December, 2020

*Corresponding author: Li-Jia Dong, School of Life Science, Shaoxing University, Shaoxing 312000, China, E-mail:Donglijia@126.com

Keywords: Biological invasions; Invasion mechanism; Multimodel inference; Nature-sieve hypothesis; Relative importance

https://www. peertechz.com

\section{Check for updates}

\section{Abstract}

Aim: Plant invasions are driven by suites of factors in nature. To better understand the success of invasive plants, it is crucial to quantify the relative importance of multiple invasion mechanisms during plant invasions.

Location: Eastern China.

Methods: We surveyed 300 pairs of uninvaded and invaded quadrats by Solidago canadensis across its entire invaded range, quantified its invasion intensities, and identified the relative importance of 19 causal factors and 11 invasion hypotheses using the multimodel inference approach.

Results: The relative contributions of all the 19 factors to $S$. canadensis invasion varied depending on different invasion intensities, so did the relative importance of 11 different hypotheses vary with invasion intensities. At the low invasion intensity, abiotic factors dominated over biotic factors; in contrast, biotic factors dominated over abiotic factors at the high invasion intensity. The role of $S$. canadensis-recipient community interactions was highly important.

Main conclusions: These findings suggest that the relative importance of multiple invasion mechanisms may be staged in a real invasion. Based on our results, we propose a novel nature-sieve hypothesis, which provides a universal framework for an understanding of successful invasion.

\section{Introduction}

The publication of the book The ecology of invasions by animals and plants by Charles Elton [1] is commonly viewed as the beginning of modern invasion ecology [2]. Ever since, the studies on biological invasions have grown exponentially [3], and, in particular, what determines invasion success has fascinated ecologists so that dozens of influential hypotheses have been proposed [4]. Numerous studies have advanced our understanding of successful invasion, but we yet fail to get a complete picture because researchers usually study different pieces of the same invasion puzzle [5]. According to the traditional paradigm, plant invasions are influenced by three aspects: propagule pressure, invader traits, and ecosystem characteristics ( $[3,6-8]$. As such, it is valuable to holistically understand the mechanisms underlying invasion success under different circumstances [3,9].

Plant invasion is conceptualized as a staged process $[7,10-$ 12]. This process is controlled by a series of causal factors that can be different depending on invasion stages $[7,12,13]$. These factors constitute a basis for different invasion hypotheses. Thus, we can explain invasion success using suites of factors or hypotheses, both of which shape invasion mechanisms; $[2,4,9,14]$. Although some ecologists have recognized that the processes driving plant invasions are likely to change over time (Dietz \& Edwards, 2006), no studies have explicitly addressed how invasion mechanisms are staged, thereby raising several important questions in a real invasion.

First, what is the relative importance of a suite of factors influencing plant invasions? It is clear that propagule pressure, invader traits, and ecosystem characteristics determine plant invasions [3,6-8]. However, little is known about the role of these three sets of factors and about the role of interactions between invaders and ecosystems in invasion success. For a given invader, its success strongly depends on its traits, ecosystem properties, and their interactions, because propagule pressure can be seen as constant [15]. Studies with 
the same species across a larger range of sites would help to reveal the full suite of factors that affect invasion [9], and their relative contributions under different circumstances should be quantified to predict or manage plant invasions $[3,16]$.

Second, what is the relative importance of multiple invasion hypotheses? It has become increasingly clear that no one individual hypothesis is sufficient to explain the invasion success of exotic plants $[3,4,17,18]$. Individual hypotheses partially overlap in mechanism and may contribute synergistically or interactively to invasions; different hypotheses are nonmutually exclusive and may also act simultaneously $[3,14,18]$. Different hypotheses usually encompass different determinants so that the importance of hypotheses should be strongly linked with the net effect of the corresponding determinants.

Finally, how might the factors driving plant invasions and the associated hypotheses vary with invasion stages? Plant invasion is a staged process, in which drivers can be different depending on the stage of invasion $([7,10-12,20]$. For a successful invader, it must experience different stages due to the spatiotemporal dynamics of determining factors. Accordingly, different invasion stages might be closely linked with different sets of filtering sieves, which shape invasion mechanisms.

To answer these questions, we quantified the extent of Solidago canadensis invasion and determined 19 causal factors across its entire range. The purpose of the current study was to quantify the relative importance of multiple mechanisms at different invasion intensities and to propose an invasion hypothesis. Specifically, we could determine what explanatory variables dominate over others in driving invasion, identify whether different hypotheses explain the success of $S$. canadensis invasions equally or differentially, and assess how the relative importance of causal factors and invasion hypotheses varies with invasion stages.

\section{Methods}

\section{Study species and region}

Solidago canadensis L. is among the most serious invasive plants in China, which was introduced from North America as an ornamental plant in 1935 [21]. This invader has now invaded large areas of southern China, such as Jiangsu, Shanghai, Zhejiang, Jiangxi, and Anhui; it occurs along roadsides or in abandoned agricultural fields and other disturbed habitats [22]. The entire invaded range belongs to a subtropical climate. Our study region roughly covered an area of $800 \times 800 \mathrm{~km}$, and the elevation ranged from $3 \mathrm{~m}$ to $79 \mathrm{~m}$.

\section{Field survey and soil analyses}

To quantify the extent of successful invasion and the relative importance of multiple invasion mechanisms, we surveyed 300 pairs of uninvaded and invaded quadrats by $S$. canadensis across its entire invaded range from July to September 2014 [22]. Solidago canadensis was the only one invader in the sampling sites. During the investigation, species cover, population density, and plant height in a quadrat were recorded; specific fine root area (SRA) and leaf traits (leaf area, Specific Leaf Area [SLA], Leaf Dry Matter Content [LDMC], chlorophyll, leaf C, leaf $\mathrm{N}$, and leaf $\mathrm{C}: \mathrm{N}$ ) of $\mathrm{S}$. canadensis in 300 invaded quadrats were determined. To measure these traits, we sampled five roots and 30 leaves per quadrat. See Cornelissen, et al. [23] for the details about determining these traits. We sampled soils from each quadrat for measurements of their biotic and biotic properties.

For soil microbes, we employed the Phospholipid Fatty Acid (PLFA) analysis [22]. Previous studies have suggested that the fatty acid $18: 2 \omega 6,9 \mathrm{c}$ can indicate soil saprotrophic pathogens and that $16: 1 \omega 5$, cy17:0, and cy19:0 can indicate soil beneficial microbes [24-27]. Accordingly, we chose 18:2 $\omega 6,9 \mathrm{c}$ as pathogens, and 16:105, cy17:0, and cy19:0 as beneficial microbes. Additionally, the fatty acid $18: 2 \omega 6,9 \mathrm{c}$ is dominant in fungi [28]. We calculated the fungi:bacteria ratio using the ratio of $18: 2 \omega 6,9 \mathrm{c}$ to bacterial PLFAs [22].

For soil abiotic properties, we measured $\mathrm{pH}$ in a soil solution rate of 1:2.5 (soil:distilled water) using a $\mathrm{pH}$ meter (Sartorius PB-10 meter), soil texture using a laser particle size analyzer (Mastersizer 2000), Available Phosphorus (AP) using a UV2550 ultraviolet spectrophotometer, and ammonia $\left(\mathrm{NH}_{4}-\mathrm{N}\right)$ and nitrate $\left(\mathrm{NO}_{3}-\mathrm{N}\right)$ using a continuous flow analyzer.

\section{Data analyses}

To quantify the success of S. canadensis invasion, we coined a relative invasion index (RII) as follows:

$$
R I I=\left\{\frac{C i}{\operatorname{Max}(C i)}+\frac{D i}{\operatorname{Max}(D i)}+\frac{H i}{\operatorname{Max}(H i)}\right\} / 3
$$

where $\mathrm{Ci}, \mathrm{Di}$, and $\mathrm{Hi}$ represent cover, density, and height of $S$. canadensis in invaded quadrats, respectively. We ranked RII values in the ascending order, and then categorized 300 invaded quadrats into three groups, representing three invasion intensities/stages. The quadrats from 1 to 100 were treated as intensity I, quadrats from 101 to 200 as intensity II, and quadrats from 201 to 300 as intensity III. We calculated the mean and standard error of RII values for each invasion intensity, and tested whether there were differences in RII among three intensities using a one-way analysis of variance. RII values were treated as a response variable in the following data analyses.

To quantify the relative contribution of determinants to invasion success (i.e. RII), we categorized these determinants into five different sets: invader traits, climate, native plant communities, soil abiotic and biotic properties, and invadercommunity interactions. We calculated a phenotypic variation index (PVI) and leaf tradeoff index (LTI) as follows:

$$
P V I=\sum_{j \equiv 1}^{8} \frac{\operatorname{Max}(T i)-T i}{\operatorname{Max}(T i)-\operatorname{Min}(T i)} / 8
$$

$$
L T I=L D M C / S L A(3)
$$


where Ti represents a given trait of the $i^{\text {th }}$ quadrat $(i=1$, $2, \ldots ., 300$ ), and Max (Ti) and Min (Ti) represent the maximum and minimum values of a specific trait among 300 quadrats. $j$ represents SRA, leaf area, SLA, LDMC, chlorophyll, leaf C, leaf $\mathrm{N}$, and leaf C:N, respectively. We used the average PVI of eight traits to indicate the phenotypic variation of S. canadensis. In general, SLA is related to the growth potential of a leaf and LDMC is related to its stress potential [23]. Thus, we used the ratio of LDMC to SLA to indicate a leaf tradeoff. Climatic data (i.e. mean annual temperature [MAT] and mean annual precipitation [MAP]) were collected from the nearest sampling sites. Native plant diversity (i.e. native species richness, Pielou evenness index, and dominance index) was calculated as described by Dong, et al. [22]. Soil microbes included beneficial microbes, pathogens, and fungi/bacteria ratio. Soil abiotic properties included soil $\mathrm{pH}$, soil texture (i.e. clay\%:silt\%:sand\%), and soil nutrients (i.e. the sum of $\mathrm{AP}, \mathrm{NH}_{4}-\mathrm{N}$, and $\mathrm{NO}_{3}-\mathrm{N}$ ). To quantify $S$. canadensis-recipient community interactions, we calculated the relative changes in native plant diversity (i.e. $\Delta$ richness), soil abiotic properties (i.e. $\Delta \mathrm{pH}$ and $\Delta$ nutrients), and soil microbes (i.e. $\Delta$ beneficial microbes, $\Delta$ pathogens, and $\Delta$ fungi/bacteria ratio). All the relative changes were calculated as follows:

$$
\Delta=\frac{V i-V u}{V i+V u}
$$

where $V i$ and $V u$ represent a given trait in the pairwise invaded and uninvaded quadrats, respectively.

To evaluate the relative contributions of different determinants to the invasion success of $S$. canadensis, we selected the Multimodel Inference (MMI) approach, which is based on all the models in a priori set, not just the one estimated to be best, and therefore can provide more stable and reliable inference results than traditional statistical inference [29]. Additionally, this approach does not explicitly determine whether individual variables are statistically significant but ranks parameters based on their ability to explain variation [30].

We used separate models for intensities I, II, III, and across all three intensities to quantify the relative contribution of 19 determinants to $S$. canadensis invasion along the invasion intensity. Specifically, the global models included one dependent variable (i.e. RII) and 19 explanatory variables (i.e. PVI, LTI, MAT, MAP, richness, evenness, dominance, $\mathrm{pH}$, texture, nutrients, beneficial microbes, pathogens, $\mathrm{F} / \mathrm{B}$ ratio, $\Delta$ richness, $\Delta \mathrm{pH}, \Delta$ nutrients, $\Delta$ beneficial microbes, $\Delta$ pathogens, and $\Delta$ F/B ratio). We used the model selection method to generate all possible candidate models from the global models. All the candidate models were then ranked according to the second-order Akaike's information criterion. The effect size of each determinant was expressed by the averaged model parameters deriving from accumulated model probability exceeded $95 \%$. The importance of each determinant was estimated by summing the Akaike's weights of each model. The relative contribution of a given factor was estimated through dividing its importance by the total importance of 19 factors.

To contrast the relative importance of different invasion hypotheses, we standardized the contribution of factors that are involved in each invasion hypothesis. Specifically, we quantified the per capita contribution of a set of factors, thereby allowing us to compare the relative importance of different invasion hypotheses. See the figure legends of Figure 3 for more details.

All statistical analyses were performed using $\mathrm{R}$ version 3.3.1 [31]. The MMI approach was performed using dredge function in the package MuMIn [32].

\section{Results}

The RII values ranged from $29.8 \%$ to $57.3 \%$ at the invasion intensity I, ranged from $57.4 \%$ to $65.7 \%$ at the intensity II, and ranged from $65.8 \%$ to $86.3 \%$ at the intensity III; the grand mean of RII was $61.9 \pm 0.7 \%$ [ $1 \mathrm{SE}$ ] ( Figure 1a). There were significant differences in RII among three intensities ( Figure 1b: $46.5 \pm 0.8 \%$ at intensity I; $61.8 \pm 0.4 \%$ at intensity II; 77.2 $\pm 0.7 \%$ at intensity III).
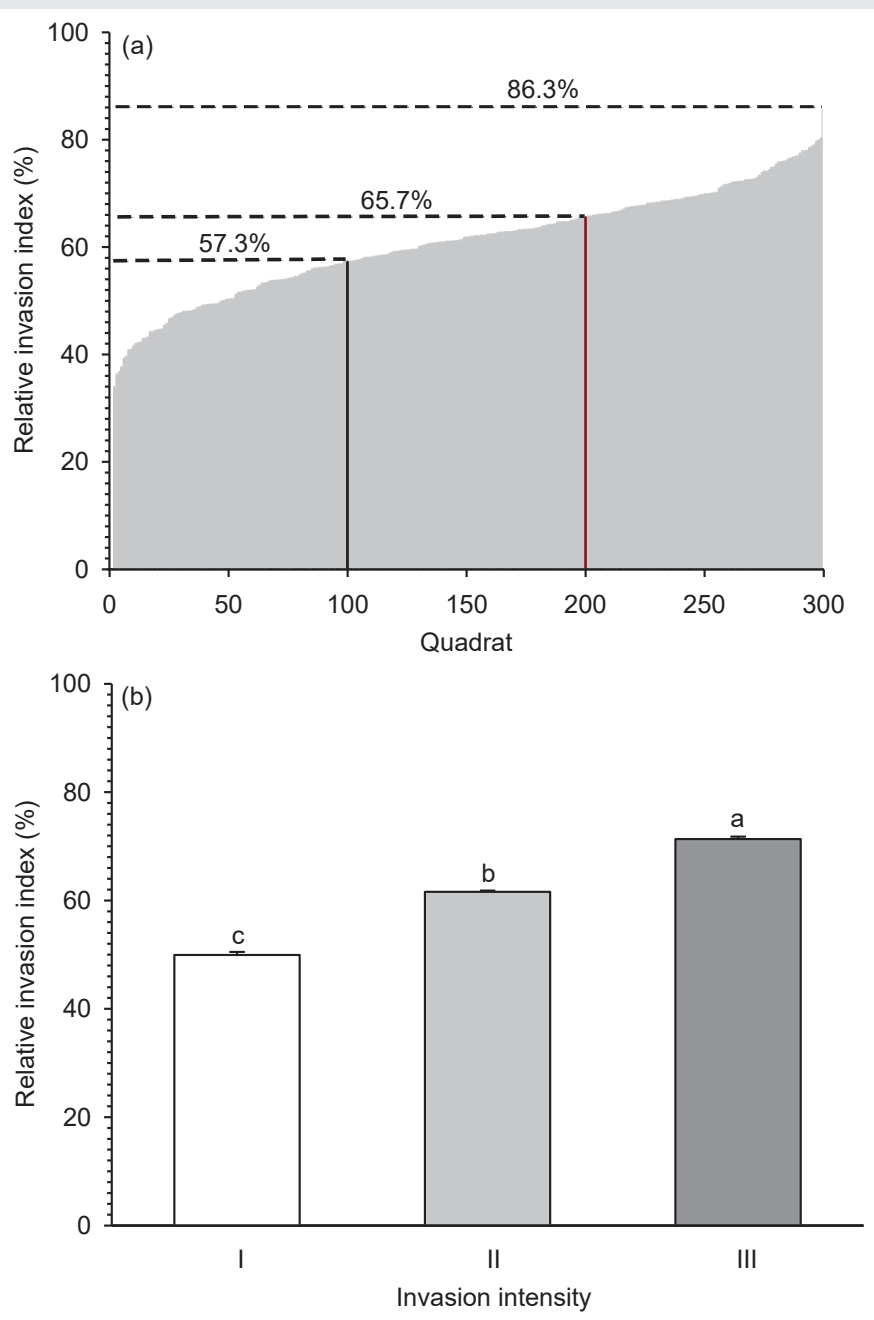

Figure 1: Relative invasion index (RII) of Solidago canadensis from 300 quadrats (a), and comparisons of RIl among three invasion intensities (b). All the quadratswere ranked in the ascending RII order in the upper panel. Data are means +1 SE $(n=100)$ and different letters indicate significant differences at $\mathrm{P}=0.05$ in the lower panel.

Citation: Zhao YF, Zhou SQ, Wei ZF, Zhao BS, Dong LJ (2020) The relative importance of multiple invasion mechanisms. Glob J Ecol 5(1): 139-145. 
There were three patterns for the relative contributions of 19 factors to RII along the invasion intensity. First, the relative contributions fluctuated slightly; four factors followed this pattern, that is, phenotypic variation (Figure 2a), soil texture (Figure 2i), and the changes in soil pathogens (Figure 2r) and fungi/bacteria (Figure 2s). Second, the relative contributions fluctuated modestly; five factors followed this pattern, that is, leaf tradeoff (Figure 2b), soil pH (Figure 2h), soil-borne pathogens (Figure 2l), fungi/bacteria (Figure 2m), and the change in soil nutrients (Figure 2p). Third, the relative contributions of the remaining ten factors increased or decreased with invasion intensity dramatically.

At the intensity I, the predominant factors contributing to RII were MAT (Figure 2c), MAP (Figure 2d), and the change in soil $\mathrm{pH}$ (Figure $2 \mathrm{~h}$ ); they accounted for $35.3 \%$ of the total contribution. At the intensity II, the predominant drivers included native species richness (Figure 2e), species evenness (Figure 2f), and species dominance (Figure 2g); they accounted for $29.7 \%$ of the total contribution. At the intensity III, the predominant factors covered native species evenness (Figure 2f), species dominance (Figure $2 \mathrm{~g}$ ), and the change in native species richness (Figure 2n); they accounted for $36.7 \%$ of the total contribution. Across all three intensities, the dominant factors were leaf tradeoff (Figure 2b), MAT (Figure 2c), soil nutrients (Figure $2 \mathrm{j}$ ), and the change in species richness (Figure 2n); their contributions were extremely similar (ca. 8.7\%). The overall contribution of $S$. canadensis traits, climate, native plant communities, soils, and S. canadensis-recipient community interactions to RII was $15.4 \%, 15.9 \%, 16.3 \%, 27.0 \%$, and $25.4 \%$, respectively.

The relative importance of different invasion hypotheses was assessed on a per capita contribution basis. Overall, no hypothesis maintained the same ranking among three invasion intensities, and the relative importance of each hypothesis always differed depending on invasion intensities (Figure 3). At the intensity I, the temperature constraint hypothesis (14.9\%) was overwhelming, and the importance of other hypotheses ranged from $6.0 \%$ for invader-community interactions to $3.0 \%$ for soil pH (Figure 3a). At the intensity II, the biotic resistance hypothesis $(9.9 \%)$ was predominant, and the importance of other hypotheses ranged from $5.4 \%$ for temperature to $3.3 \%$ for soil texture (Figure 3b). At the intensity III, the biotic resistance hypothesis (9.5\%) was also predominant, and the importance of other hypotheses ranged from $6.8 \%$ for temperature to $2.7 \%$ for belowground mutualism (Figure 3c). Across all three intensities, the predominant hypotheses were: temperature constraint $(8.8 \%)$ and reckless invader $(8.8 \%)$, and the importance of other hypotheses ranged from $7.9 \%$ for increased resource availability to $3.0 \%$ for soil texture (Figure 3d).

\section{Discussion}

The most novel contribution of our results is that 19 determining factors contributed differentially to the invasion success of $S$. canadensis and their contributions varied with invasion intensities. These findings suggest that all the driving forces, particularly dominants, vary with invasion stages, because invasion intensities and invasion stages are strongly
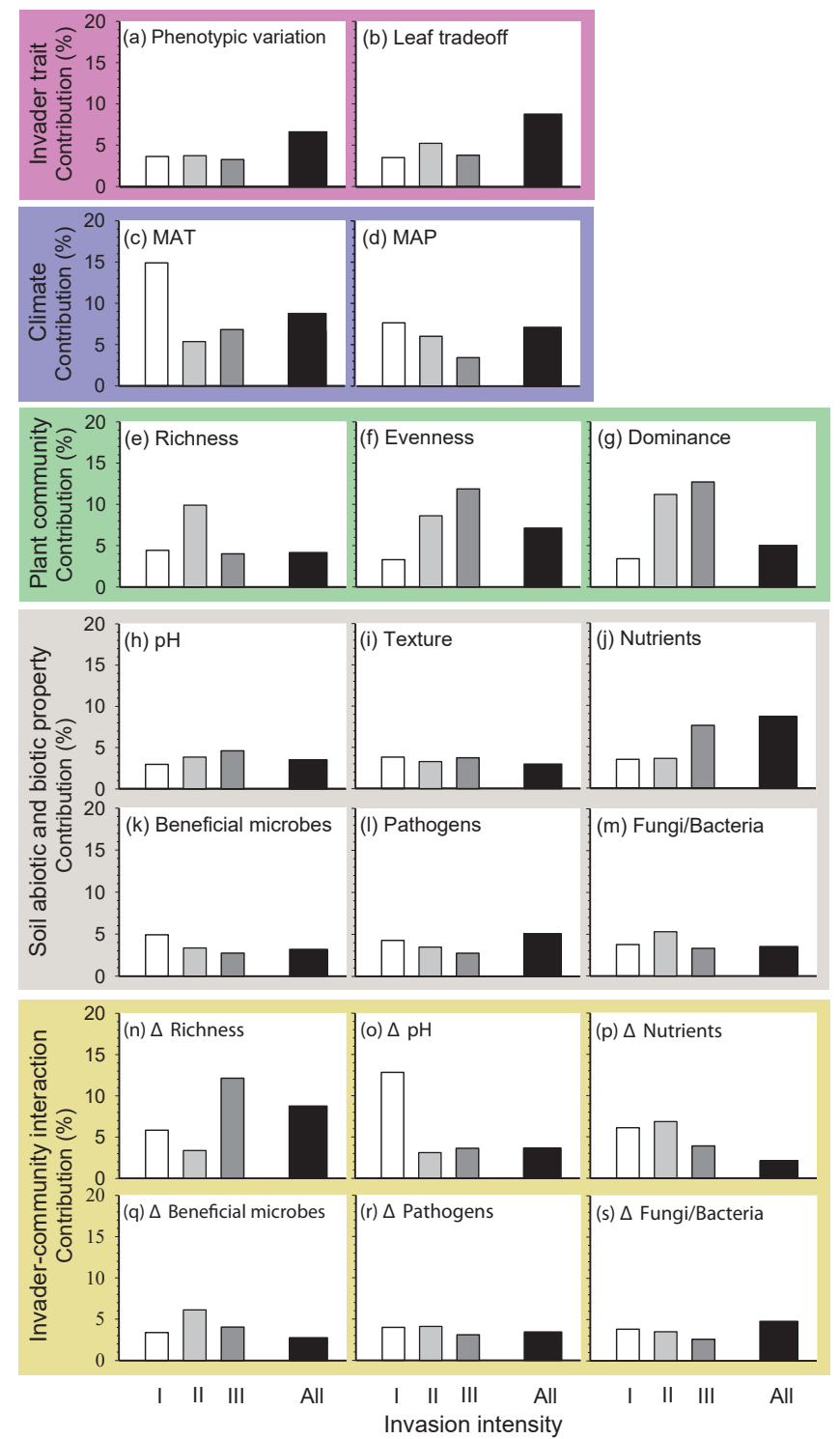

Figure 2: The relative contributions of 19 factors to the success of Solidago canadensis invasion. MAT: mean annual temperature; MAP: mean annual precipitation.

correlated [3,7]. For example, at the earlier invasion stage, abiotic factors (e.g. climate) dominated over other factors; at the later stage, biotic factors (e.g. plant diversity) dominated over other factors. We also observed that many non-dominant factors exhibited modest contributions to $S$. canadensis invasion. This finding is in agreement with a previous meta-analysis that multiple factors lead to the success of invasive trees [9]. Additionally, the relative contribution of causal factors may depend on the scale of the investigation [5].

A second key result of our study was that the relative importance of multiple hypotheses varied with invasion stages and multiple hypotheses explained invasion success. We quantified the relative importance of 11 hypotheses based on the per capita contribution of the factors reflecting a given invasion hypothesis. The temperature constraint hypothesis was overwhelming at the first stage, and biotic resistance was predominant at the second and third stages. These results support the viewpoints that the relative importance of various 


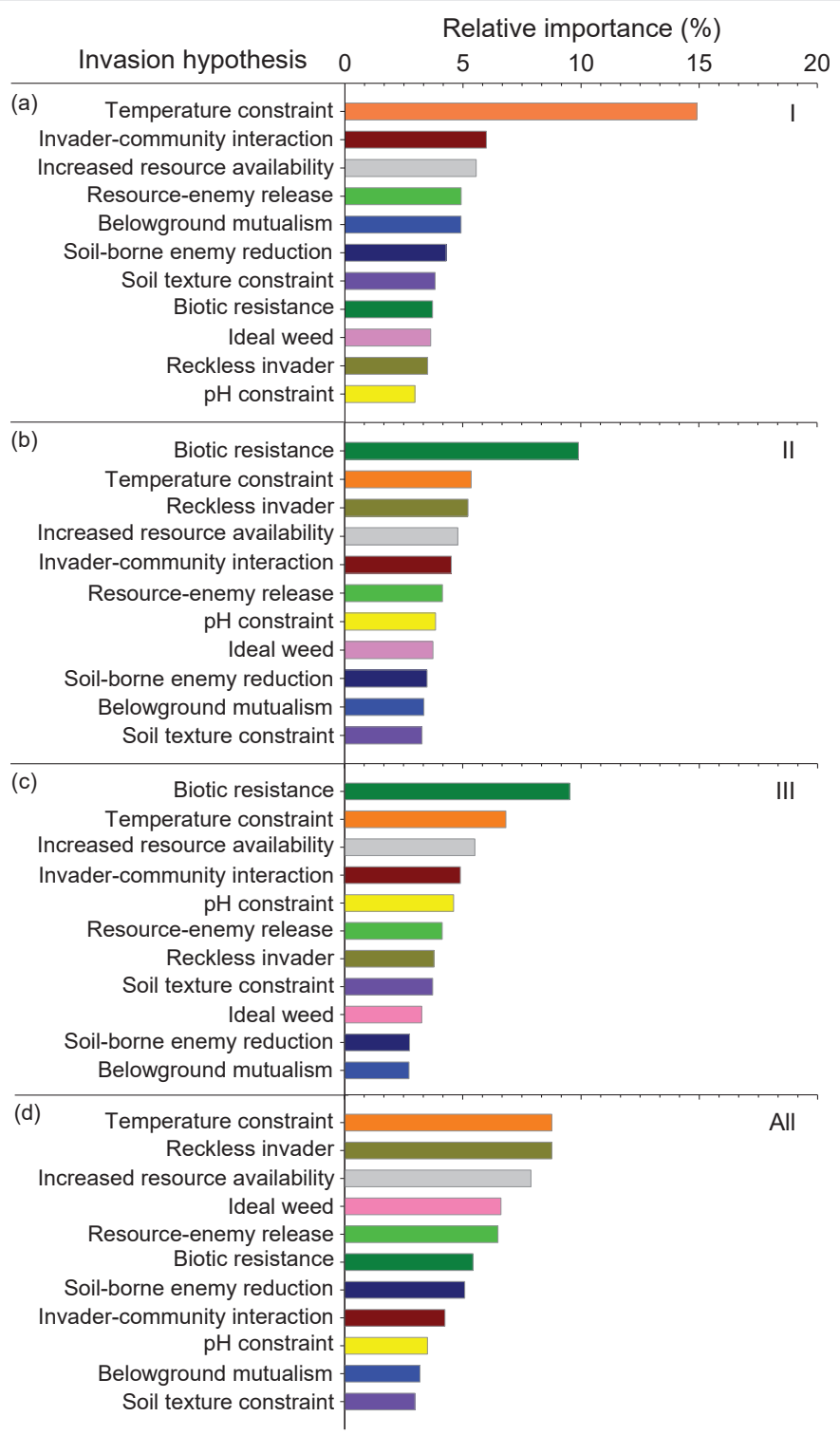

Figure 3: The relative importance of 11 invasion hypotheses during Solidago canadensis invasion. The ideal weed hypothesis is based on the contribution of phenotypic variation; reckless invader hypothesis based on the contribution of leaf tradeoff; temperature constraint hypothesis based on the contribution of MAT; biotic resistance hypothesis based on the mean contribution of native plant diversity; $\mathrm{pH}$ constraint hypothesis based on the contribution of soil $\mathrm{pH}$; soil texture constraint hypothesis based on the contribution of soil texture; increased resource availability hypothesis based on the mean contribution of MAP and soil nutrients; belowground mutualism hypothesis based on the contribution of beneficial microbes; soil-borne enemy reduction based on the contribution of soil pathogens; resource-enemy release hypothesis based on the mean contribution of MAP, nutrients, and pathogens; invader-community interaction hypothesis based on the mean contribution of the relative changes in native plant richness and soil properties.

mechanisms varies depending on invasion stages and the inconsistencies in the results from testing plant invasion hypotheses can potentially be resolved by partitioning of the invasion stages [7]. We found that many hypotheses explained invasion success similarly, suggesting that the success of a given invader can be explained with multiple hypotheses but not one only $[13,14,17,19]$. Additionally, leading hypotheses did not equally explain plant invasions. This phenomenon has been reported by Lamarque, et al. [9].
We observed that the $S$. canadensis-recipient community interactions played a key role in driving its invasion. Specifically, the contribution of this interaction accounted for about $25 \%$ of the total contribution of all factors, regardless of at intensities I, II, and III or across three intensities. This role was tightly correlated with the changes in native species and soil abiotic properties. Although soil microbes commonly play an important role in plant invasions [33-35], we found that the contribution of changing soil microbes was relatively low. Our results are exceptionally valuable because previous studies have overlooked the key role of this interaction.

We propose several possibilities that might explain our results. First, environmental factors constitute suites of filtering sieves; at a given phase, there are a set of factors that dominate over others and are most influential [36]. For example, at the earlier invasion stage, suitable climate is predominant; suitable biological environments are predominant at the later stage. Thus, there exist a series of filtering sieves, which vary with invasion stages. Second, multiple factors/processes contribute to invasion success. This is beneficial to decrease the dependence of invasion success on the predominant determinants and to spread the potential risks of failure. In other words, multiple mechanisms facilitate successful invasion jointly. Lastly, if the invasion is processing into more closed communities, environmental pressures may favor invasive species [7].

Our findings have three implications. One important corollary of our results is that plant invasion may be a stochastic but not deterministic process and invasion trajectories may be unpredictable. As some ecologists point out: invasions are intrinsically unpredictable because every case is unique [7]. The processes driving plant invasion are variable so that the knowledge of the mechanisms operating at the primary phase may be little use in predicting what happens later [7]. Thus, predicting invasion remains a challenge, and invasion history matters [37]. The second implication is that our findings provide evidence for those apparent conflicting results. For example, in some cases abiotic constraints overwhelmingly determine invasion success [38], and biotic factors predominate in other cases [39]; inconsistent results may come from different invasion stages, although the same factors/hypotheses are addressed. Finally, one promising way of investigating how species' responses change from one stage to another is to study the ecology of invasive species along strong environmental gradients, particularly at a regional scale [7].

It is obvious that 19 factors are just a small proportion of determinants shaping invasion success. These factors can indicate multiple hypotheses that represent part of existing hypotheses [4]. Our findings cannot exclude other invasion mechanisms because invasion processes are extremely complicated and dynamic. For example, herbivores play a key role in controlling plant invasions [40], allelochemicals from roots can facilitate plant invasions $[14,19]$, disturbance is a key driver for invasion success [41], and clonal growth and propagation may be an advantage for clonal invaders. However, these mechanisms were not considered in our study due to the lack of data. 


\section{Conclusion}

Our study provides a first basis for understanding how invader traits, climate, native plant diversity, soil abiotic and biotic properties, and interactions between invasive plants and recipient communities contribute to invasion success at different invasion intensities. Our findings suggest that the relative importance of multiple invasion mechanisms may be staged. Based on our results, we put forward a novel naturesieve hypothesis. This hypothesis can link the internal attributes of invaders and external environmental sieves together. Invader attributes include suites of intrinsic traits like growth potential, competitive ability, and releasing allelochemicals. Environmental sieves are basically characterized by hierarchy. For example, environmental sieves encompass biotic and abiotic ones, which contain multiple components/subcomponents. The nature-sieve hypothesis is likely to provide a universal framework for complete understanding of invasion success in a real invasion.

\section{Acknowledgements}

This study was financially supported by grants from National Natural Science Foundation of China (31700476).

\section{References}

1. Elton CS (1958) The ecology of invasions by animals and plants. Methuen, London. Link: https://bit.ly/37sAMTO

2. Jeschke JM (2014) General hypotheses in invasion ecology. Diversity and Distributions 20: 1229-1234. Link: http://bit.ly/33NdWnl

3. Gurevitch J, Fox GA, Wardle GM, Inderjit, Taub D (2011) Emergent insights from the synthesis of conceptual frameworks for biological invasions. Ecol Lett 14: 407-418. Link: https://bit.ly/3mHjEzO

4. Catford JA, Jansson R, Nilsson C (2009) Reducing redundancy in invasion ecology by integrating hypotheses into a single theoretical framework. Diversity and Distributions 15: 22-40. Link: http://bit.ly/33HRDiH

5. Milbau A, Stout JC, Graae BJ, Nijs I (2009) A hierarchical framework for integrating invasibility experiments incorporating different factors and spatial scales. Biological Invasions 11: 941-950. Link: https://bit.ly/2I3zrKu

6. Davis MA, Grime JP, Thompson K (2000) Fluctuating resources in plant communities: a general theory of invasibility. Journal of Ecology 88: 528-534. Link: https://bit.ly/39A3PXZ

7. Dietz H, Edwards PJ (2006) Recognition that causal processes change during plant invasion helps explain conflicts in evidence. Ecology 87: 1359-1367. Link: https://bit.ly/3mwmrvJ

8. Byun C, de Blois S, Brisson J (2015) Interactions between abiotic constraint, propagule pressure, and biotic resistance regulate plant invasion. Oecologia 178: 285-296. Link: https://bit.ly/2Vn9gBo

9. Lamarque LJ, Delzon S, Lortie CJ (2011) Tree invasions: a comparative test of the dominant hypotheses and functional traits. Biological Invasions 13: 1969-1989. Link: https://bit.ly/3fWamNU

10. Richardson DM, Pyšek P, Rejmánek M, Barbour MG, Panetta FD, et al. (2000) Naturalization and invasion of alien plants: concepts and definitions. Diversity and Distributions 6: 93-107. Link: https://bit.ly/33zPqr8

11. Colautti RI, Maclsaac HJ (2004) A neutral terminology to define 'invasive' species. Diversity and Distributions 10: 135-141. Link: https://bit.ly/39tigNI
12. Theoharides KA, Dukes JS (2007) Plant invasion across space and time: factors affecting nonindigenous species success during four stages of invasion. New Phytologist 176: 256-273. Link: https://bit.ly/37urSFI

13. Wang C, Jiang K, Liu J, Zhou J, Wu B (2018) Moderate and heavy, solidago canadensis $\mathrm{L}$. invasion are associated with decreased taxonomic diversity but increased functional diversity of plant communities in east china. Ecological Engineering 112: 55-64. Link: https://bit.ly/37o2Yas

14. Zheng YL, Feng YL, Zhang LK, Callaway RM, Valiente-Banuet A, et al. (2015) Integrating novel chemical weapons and evolutionarily increased competitive ability in success of a tropical invader. New Phytol 205: 1350-1359. Link: https://bit.ly/3qmBhao

15. Gebrekiros MG, Tessema ZK (2018) Effect of senna obtusifolia (L.) invasion on herbaceous vegetation and soil properties of rangelands in the western tigray, northern ethiopia. Ecological Processes 7: 9. Link: https://bit.ly/2VosQx0

16. Hoffberg SL, Mauricio R, Hall RJ (2018) Control or re-treat? model-based guidelines for managing established plant invasions. Biological Invasions 20: 1387-1402. Link: https://bit.ly/2JBrmx3

17. Wang R, Wang JF, Qiu ZJ, Meng B, Wan FH, et al. (2011) Multiple mechanisms underlie rapid expansion of an invasive alien plant. New Phytologist 191: 828839. Link: https://bit.ly/3fW5F60

18. Lau JA, Schultheis EH (2015) When two invasion hypotheses are better than one. New Phytologist 205: 958-960. Link: https://bit.ly/36uotao

19. He WM, Feng YL, Ridenour WM, Thelen GC, Pollock JL, et al. (2009) Novel weapons and invasion: biogeographic differences in the competitive effects of Centaurea maculosa and its root exudate (+/-)-catechin. Oecologia 159: 803-815. Link: https://bit.ly/33zHh68

20. Seipel T, Rew LJ, Taylor KT, Maxwell BD, Lehnhoff EA, et al. (2018) Disturbance type influences plant community resilience and resistance to Bromus tectorum invasion in the sagebrush steppe. Applied Vegetation Science 21: 385-394. Link: https://bit.ly/3fZna6i

21. Dong M, Lu JZ, Zhang WJ, Chen JK, Li B (2006) Canada goldenrod (Solidago canadensis): An invasive alien weed rapidly spreading in China. Acta Phytotaxonomica Sinica 44: 72-85. Link: http://bit.ly/30mVAHG

22. Dong LJ, Yu HW, He WM (2015) What determines positive, neutral, and negative impacts of Solidago canadensis invasion on native plant species richness Scientific Reports 5: 16804. Link: https://go.nature.com/36sBH7b

23. Cornelissen JHC, Lavorel S, Garnier E, Diaz S, Buchmann N, et al. (2003) A handbook of protocols for standardised and easy measurement of plant functional traits worldwide. Australian Journal of Botany 51: 335-380. Link: https://bit.ly/37viWQ9

24. Olsson PA, Baath E, Jakobsen I (1997) Phosphorus effects on the mycelium and storage structures of an arbuscular mycorrhizal fungus as studied in the soil and roots by analysis of fatty acid signatures. Applied and Environmental Microbiology 63: 3531-3538. Link: https://bit.ly/39A9ttk

25. Larsen J, Olsson PA, Jakobsen I (1998) The use of fatty acid signatures to study mycelial interactions between the arbuscular mycorrhizal fungus Glomusintraradices and the saprotrophic fungus Fusarium culmorum in rootfree soil. Mycological Research, 102: 1491-1496. Link: https://bit.ly/3qIE5os

26. Larsen J, Mansfeld-Giese K, Bodker L (2000) Quantification of Aphanomyces euteiches in pea roots using specific fatty acids. Mycological Research 104: 858-864. Link: https://bit.ly/3fVOaDN

27. Larsen J, Ravnskov S, Jakobsen I (2003) Combined effect of an arbuscular mycorrhizal fungus and a biocontrol bacterium against Pythium ultimum in soil. Folia Geobotanica 38: 145-154. Link: https://bit.ly/3muMbJ9

28. Muller MM, Kantola R, Kitunen V (1994) Combining sterol and fatty-acid profiles for the characterization of fungi. Mycological Research 98: 593-603. Link: https://bit.ly/2JAoEHY 
29. Burnham KP, Anderson DR (2002) Model selection and multimodel inference: a practice information-theoretic approach. New York: Springer-Verlag. Link: https://bit.ly/36rwOeQ

30. Pinto H, Powell JR, Sharwood RE, Tissue DT, Ghannoum O (2016) Variations in nitrogen use efficiency reflect the biochemical subtype while variations in water use efficiency reflect the evolutionary lineage of C-4 grasses at interglacial CO2. Plant Cell Environ 39: 514-526. Link: https://bit.ly/3ojiXNx

31. Development Core Team (2016) The R Project for Statistical Computing $\mathrm{R}$ Foundation for Statistical Computing, Vienna, Austria. Link: https://bit.ly/3qfzT9P

32. Bartoń K (2019) MuMIn: Multi-Model Inference. R package version 1.43.6 Link: https://bit.ly/3mpTe5H

33. Richardson DM, Allsopp N, D'Antonio CM, Milton SJ, Rejmanek M (2000a) Plant invasions- the role of mutualisms. Biol Rev Camb Philos Soc 75: 65-93. Link: https://bit.ly/3qnuT30

34. Traveset A, Richardson DM (2014) Mutualistic interactions and biological invasions. Annual Review of Ecology, Evolution, Systematics 45: 89-113. Link: https://bit.ly/2VnrClO

35. Li M, Wei Z, Wang J, Jousset A, Friman VP, et al. (2019) Facilitation promotes invasions in plant-associated microbial communities. Ecology Letters 22: 149-158. Link: https://bit.ly/33Cyr7z
36. Grime JP, Pierce S (2012) The evolutionary strategies that shape ecosystems Wiley-Blackwell. Link: https://bit.ly/3ltQwLf

37. Milbau A, Stout JC (2008) Factors associated with alien plants transitioning from casual, to naturalized, to invasive. Conserv Biol 22: 308-317. Link: https://bit.ly/3fYXeHS

38. Miller AL, Diez JM, Sullivan JJ, Wangen SR, Wiser SK, et al. (2013) Quantifying invasion resistance: the use of recruitment functions to control for propagule pressure. Ecology 95: 920-929. Link: https://bit.ly/3lxYO4C

39. Davies KF, Cavender-Bares J, Deacon N (2011) Native communities determine the identity of exotic invaders even at scales at which communities are unsaturated. Diversity and Distributions 17: 35-42. Link: https://bit.ly/2I0ictx

40. Keane RM, Crawley MJ (2002) Exotic plant invasions and the enemy release hypothesis. Trends in Ecology and Evolution 17: 164-170. Link: https://bit.ly/33CpHhT

41. Moles AT, Flores-Moreno H, Bonser SP, Warton DI, Helm A, et al. (2012) Invasions: the trail behind, the path ahead, and a test of a disturbing idea. Journal of Ecology 100: 116-127. Link: https://bit.ly/2JpE1Di
Discover a bigger Impact and Visibility of your article publication with Peertechz Publications

Copyright: (c) 2020 Zhao YF, et al. This is an open-access article distributed under the terms of the Creative Commons Attribution License, which permits unrestricted use, distribution, and reproduction in any medium, provided the original author and source are credited.

Citation: Zhao YF, Zhou SQ, Wei ZF, Zhao BS, Dong LJ (2020) The relative importance of multiple invasion mechanisms. Glob J Ecol 5(1): 139-145. 